\title{
Nausea and Vomiting After Strabismus-Surgery: A Randomized Comparison of Isoflurane, Enflurane, Sevoflurane and Propofol
}

\author{
P. Kranke ${ }^{*}, 1$ C.C. Apfel ${ }^{2}$, T. Papenfuss ${ }^{1}$, T. Metterlein ${ }^{1}$, F. Schuster ${ }^{1}$, R. Muellenbach ${ }^{1}$, S. Rauch ${ }^{1}$ \\ and N. Roewer ${ }^{1}$ \\ ${ }^{I}$ Department of Anesthesia and Critical Care, University Hospitals of Würzburg, Oberdürrbacher Str. 6, D-97080 \\ Wuerzburg, Germany \\ ${ }^{2}$ Perioperative Clinical Research Core, Department of Anesthesiology and Perioperative Care, University of California, \\ San Francisco, California, USA
}

\begin{abstract}
Background: Previous studies reported that propofol anesthesia is an effective means of preventing postoperative nausea and vomiting (PONV) after different types of surgeries. The present analysis of a large antiemetic trial is intend to compare propofol versus isoflurane, enflurane or sevoflurane with respect to the incidences of PONV after strabismus surgery.

Methods: 238 ASA I - III inpatients, aged 4-65 years were randomly assigned to receive either isoflurane (group I, $\mathrm{n}=$ 60 ), enflurane (group $\mathrm{E}, \mathrm{n}=59$ ), sevoflurane (group $\mathrm{S}, \mathrm{n}=59$ ) or propofol (group $\mathrm{P}, \mathrm{n}=60$ ) for maintenance as a subgroup of a larger trial of factorial design to investigate interventions to reduce PONV. After opioid application, patients in the inhalational groups (group I, E and S) had anesthesia induced with thiopental, those in group P received propofol for induction. Tracheal intubation was facilitated with succinylcholine. Patients were ventilated with $\mathrm{N}_{2} \mathrm{O} / \mathrm{O}_{2} 2: 1$. Incidence and severity of PONV as well as the need for antiemetic rescue treatment were studied during the first 24 hours after anesthesia. Paracetamol and tramadol was given to treat postoperative pain.

Results: There were no significant differences between study groups with respect to patient demographics and risk factors for postoperative nausea and vomiting. Nausea was reported by $43 \%, 41 \%, 42 \%$ and $22 \%$ of patients in groups I, E, S and $\mathrm{P}$, respectively $(P=0.043)$. The incidence of vomiting was $40 \%, 46 \%, 34 \%$ and $18 \%$ in groups I, E, S and P, respectively $(P=0.011)$.

Conclusion: Patients anesthetized with propofol showed a significantly lower incidence of nausea and vomiting compared to volatile anesthetics, while there was no significant differences in emetogenicity between the volatile anesthetics.
\end{abstract}

Keywords: Anesthesia, Isoflurane, Enflurane, Sevoflurane, Propofol, Strabismus surgery, Nausea, Vomiting, PONV.

\section{INTRODUCTION}

Postoperative nausea and vomiting (PONV) continue to be a common "big little problem" in the postoperative setting and accounts for unanticipated admission to hospital in ambulatory surgery [1] and a strong negative patient perception [2]. Despite new antiemetic drugs the overall incidences remain high especially in subjects with increased patient-related risk-factors $[3,4]$. Strabismus surgery is often associated with a remarkable high rate of PONV [5]. Though in general the influence of the surgical procedure is thought to be negligible, especially in children this surgical procedure constitutes an independent risk factor [6,7]. Furthermore, strabismus surgery is a highly standardized surgical procedure and therefore predestinated to evaluate the impact of the anesthesiological factors contributing to PONV. Propofol is associated with a lower incidence of PONV [8] though there is conflicting data about the resulting

*Address correspondence to this author at the Department of Anesthesia and Critical Care, University Hospitals of Würzburg, Oberdürrbacher Str. 6, D97080 Wuerzburg, Germany; Tel: + 49-(0)931-201/30116; Fax: +49(0)931-201/30009; E-mail: kranke_p@klinik.uni-wuerzburg.de benefit using total intravenous anesthesia versus anesthesia based on volatile agents. We therefore evaluated the effect of maintaining anesthesia with isoflurane, enflurane, sevoflurane and propofol on PONV in patients undergoing elective strabismus surgery.

\section{MATERIALS AND METHODOLOGY}

After obtaining ethical approval and written informed consent 238 ASA class I to III inpatients aged 4 to 65 years and scheduled for elective strabismus surgery were enrolled in the study. Within 24 hours prior to surgery, no patient had experienced nausea or vomiting nor had received any drug known to have antiemetic effect. Only children $\geq 4$ years of age and adults with increased patient-related risk for PONV $>20 \%$, calculated according to an established risk score were included in the study [4]. This score is able to identify patients who are particularly susceptible to PONV after inhalational anesthesia. The presented analysis was part of a research project on PONV, using a multiple stratified (factorial) designed in order to balance the investigated groups for other factors to be investigated (e.g. antiemetics). Patients were randomly assigned to one of four study groups and were unaware of the anesthetics 
administered: Group I: induction with thiopental $5 \mathrm{mg} \times \mathrm{kg}^{-1}$ and maintenance with isoflurane $\left(\right.$ Forene $\left.^{\circledR}\right)$ 0.5-2 vol.\% inspired concentration, group E: induction with thiopental $5 \mathrm{mg} \times \mathrm{kg}^{-1}$, maintenance with enflurane $\left(\right.$ Ethrane $\left.^{\circledR}\right)$ 0.5-2.5 vol.\% inspired concentration, group S: induction with thiopental $5 \mathrm{mg} \times \mathrm{kg}^{-1}$, maintenance with sevoflurane (Sevorane ${ }^{\circledR}$ ) 0.8-3 vol.\% inspired concentration and group $\mathrm{P}$ : induction with propofol $\left(\right.$ Disoprivan $\left.^{\circledR}\right) 3 \mathrm{mg} \times \mathrm{kg}^{-1}$ and maintenance with propofol 5-15 $\mathrm{mg} \times \mathrm{kg}^{-1} \mathrm{~h}^{-1}$.

Premedication and anesthesia was managed according to a standardized protocol in all groups Patients were premedicated with midazolam, $0.1 \mathrm{mg} \times \mathrm{kg}^{-1}$ p.o. (adults) or $0.5 \mathrm{mg} \times \mathrm{kg}^{-1}$ rectal (children). In the induction room ECG and NIBP monitoring was established and a venous cannula was inserted. Children's dorsum of the hands had been prepared with local anesthetic cream (prilocaine/lidocaine) 60 min earlier. After starting an IV infusion of ringer's lactate and appropriate preoxygenation via facemask, opioids were administered in a stratified manner $\left(1.5 \mu \mathrm{g} \times \mathrm{kg}^{-1}\right.$ fentanyl, $15 \mu \mathrm{g} \times \mathrm{kg}^{-1}$ alfentanil or $0.15 \mu \mathrm{g} \times \mathrm{kg}^{-1}$ sufentanil), anesthesia was induced in accordance with group allocation (concealed allocation) after two minutes. Endotracheal intubation was facilitated with succinylcholine $1.5 \mathrm{mg} \times \mathrm{kg}^{-1}$. According to randomization antiemetic prophylaxis was applied at the induction of anesthesia or after discontinuation of the primary maintenance anesthetic in a randomized, double-blind and stratified manner. Subjects received either $50 \mu \mathrm{g} \times \mathrm{kg}^{-1}$ tropisetron (max. dose: $2.5 \mathrm{mg}$ ), $1.24 \mathrm{mg} \times \mathrm{kg}^{-1}$ dimenhydrinate (max. dose: $62 \mathrm{mg}$ ), $1 \mathrm{mg} \times \mathrm{kg}^{-1}$ metoclopramide (max. dose: $50 \mathrm{mg}$ ), $50 \mu \mathrm{g} \times \mathrm{kg}$ ${ }^{-1}$ droperidol (max. dose: $2.5 \mathrm{mg}$ ) or placebo i.v. Patients were normoventilated with $\mathrm{N}_{2} \mathrm{O} / \mathrm{O}_{2} 2: 1$ aiming at end-tidal carbon dioxide concentration of $35 \mathrm{~mm} \mathrm{Hg}$. All patients were monitored by continuous ECG, NIBP, pulse oximetry and capnometry. Patients were allowed to receive repetitive doses of the opioid given at the induction as an adjunct to increase depth of anesthesia in case of the systolic blood pressure or heart rate increased more than $20 \%$ from baseline therefore in this way maximum inspired anesthetic concentrations (group I, E, S) or propofol infusion (group P) was supplied to the pateins. At the end of surgery volatile anesthetics or the propofol infusion and nitrous oxide were discontinued, and the endotracheal tube was removed, as soon as spontaneous breathing was sufficient and coughing reflexes had returned. Patients were then transferred to the recovery room. Apart from basic monitoring the assessment of PONV and pain was started.

In the recovery room nausea, pain and headache was assessed by an independent and trained observer not involved in the maintenance of the anesthesia and blinded to treatment, using a numeric rating scale (NRS) from $0=$ no complaints to 10 = nausea, pain or headache as severe as possible. Nausea was recorded if the patient was old enough to report it. Vigilance was measured using a modified Glasgow-Coma-Scale. These assessments were made 10, 30, 60 and $120 \mathrm{~min}$ after extubation as well as 6 and 24 hours on the ward. Emetic episodes were continuously observed and recorded and were defined as retching and / or vomiting within five minutes. Patients experiencing more than two emetic episodes and / or severe nausea (NRS $\geq 4$ ) or requested an antiemetic, were given an appropriate dose of rescue medication (tropisetron or dimenhydrinate). This was repeated if indicated. Pain was treated with repetitive doses of paracetamol rectal (max.: $80 \mathrm{mg} \times \mathrm{kg}^{-1}$ day ${ }^{-1}$ ) and IV tramadol (max.: $6 \mathrm{mg} \times \mathrm{kg}^{-1}$ day $^{-1}$ ). All side effects and adverse events during the study period were recorded.

The presented analysis aimed at investigating the influence of the maintenance agent (isoflurane, enflurane, sevoflurane or propofol) on the occurrence of PONV in patients undergoing elective strabismus surgery in an univariate analysis. The null hypothesis was that propofol does not decrease the incidence of PONV. Secondary analysis should be performed investigating the effect of the different inhalational anesthetics as well as the effect of the investigated anesthetics on distinct time intervals.

For statistical analysis, nonparametric data are presented as median with lower and upper quartiles $\left(\mathrm{Q}_{1}, \mathrm{Q}_{3}\right)$. Binary data are represented as proportions with $95 \%$ confidence interval $(\mathrm{CI})$ or as number and percentage. Chi-square test was employed to compare categorical data of the main outcome variables (PON, POV, PONV, rescue antiemetics). A $P$-value of less than 0.05 was considered statistically significant.

An overall power analysis was done for the whole factorial trial design [9]. The present dataset investigating the influence of the administered anesthetics on the incidence of overall PONV (main outcome) had a $\beta$-value of 0.2 and an $\alpha$-value of 0.05 , assuming a reduction of PONV from $60 \%$ to $30 \%$ (minimum required sample size: 49 patients).

\section{RESULTS}

The four study groups were comparable with respect to demographic data and patient-related risk factors contributing to PONV (Table 1).

Table 1. Demographic Data of Patients Participating in the Study

\begin{tabular}{|l|c|c|c|c|}
\hline Characteristic & $\begin{array}{c}\text { Group I } \\
\mathbf{n}=\mathbf{6 0}\end{array}$ & $\begin{array}{c}\text { Group E } \\
\mathbf{n}=\mathbf{5 9}\end{array}$ & $\begin{array}{c}\text { Group S } \\
\mathbf{n}=\mathbf{5 9}\end{array}$ & $\begin{array}{c}\text { Group P } \\
\mathbf{n}=\mathbf{6 0}\end{array}$ \\
\hline \hline $\begin{array}{l}\text { Age } \\
\text { (year) }\end{array}$ & $8(5-20)$ & $6(5-16)$ & $6(5-19)$ & $7(5-24)$ \\
\hline $\begin{array}{l}\text { Children } \\
(\leq 16 \text { years })\end{array}$ & $43(72 \%)$ & $46(78 \%)$ & $44(75 \%)$ & $42(70 \%)$ \\
\hline $\begin{array}{l}\text { Adults } \\
(\geq 17 \text { years) }\end{array}$ & $17(28 \%)$ & $13(22 \%)$ & $15(25 \%)$ & $18(30 \%)$ \\
\hline $\begin{array}{l}\text { Sex } \\
\text { (m/f) }\end{array}$ & $30 / 30$ & $30 / 29$ & $30 / 29$ & $30 / 30$ \\
\hline $\begin{array}{l}\text { Height } \\
\text { (cm) }\end{array}$ & $130(117-166)$ & $128(115-158)$ & $121(113-160)$ & $129(116-$ \\
\hline $\begin{array}{l}\text { Weight } \\
\text { (kg) }\end{array}$ & $27(21-62)$ & $25(20-55)$ & $23(20-54)$ & $29(20-63)$ \\
\hline $\begin{array}{l}\text { ASA status } \\
(\mathrm{I} / I I)\end{array}$ & $35 / 25$ & $39 / 20$ & $50 / 9$ & $48 / 12$ \\
\hline $\begin{array}{l}\text { History of } \\
\text { PONV }\end{array}$ & $10(17 \%)$ & $9(15 \%)$ & $9(15 \%)$ & $16(26 \%)$ \\
\hline $\begin{array}{l}\text { Motion } \\
\text { sickness }\end{array}$ & $8(13 \%)$ & $16(27 \%)$ & $8(14 \%)$ & $10(16 \%)$ \\
\hline Smoker & $3(5 \%)$ & $5(8 \%)$ & $2(3 \%)$ & $5(8 \%)$ \\
\hline
\end{tabular}

Data are presented as number of patients (\%) or median (lower-upper quartiles). 
Table 2. Anesthesia Related Data and Overall Emetic Symptoms

\begin{tabular}{|c|c|c|c|c|c|}
\hline Characteristic & $\begin{array}{c}\text { Group I } \\
\mathbf{n}=\mathbf{6 0}\end{array}$ & $\begin{array}{c}\text { Group E } \\
\mathbf{n}=\mathbf{5 9}\end{array}$ & $\begin{array}{c}\text { Group } \mathbf{S} \\
\mathbf{n}=\mathbf{5 9}\end{array}$ & $\begin{array}{c}\text { Group P } \\
\mathbf{n}=\mathbf{6 0}\end{array}$ & $P$-Value \\
\hline \multicolumn{6}{|c|}{ Antiemetics (tropisetron, dimenhydrinate, metoclopramide, droperidol, placebo) } \\
\hline - prior to induction & $(6 / 6 / 6 / 6 / 6)$ & $(6 / 6 / 6 / 6 / 6)$ & $(6 / 6 / 6 / 6 / 6)$ & $(6 / 6 / 6 / 6 / 6)$ & \\
\hline - at the end of aneasthesia & $(6 / 6 / 6 / 6 / 6)$ & $(5 / 6 / 6 / 6 / 6)$ & $(5 / 6 / 6 / 6 / 6)$ & $(6 / 6 / 6 / 6 / 6)$ & \\
\hline PACU stay (min) & $65(49-88)$ & $60(37-87)$ & $80(63-100)$ & $60(36-74)$ & \\
\hline PON (0-24 hrs) & $26(43 \%)$ & $24(41 \%)$ & $25(42 \%)$ & $13(22 \%)$ & $P=0.043$ \\
\hline POV (0-24 hrs) & $24(40 \%)$ & $27(46 \%)$ & $20(34 \%)$ & $11(18 \%)$ & $P=0.011$ \\
\hline PONV (0-24 hrs) & $35(58 \%)$ & $35(59 \%)$ & $28(48 \%)$ & $17(28 \%)$ & $P=0.002$ \\
\hline
\end{tabular}

Data are presented as number of patients (\%) or median (lower-upper quartiles).

There were no significant differences between the groups with respect to anesthesia (Table 2). Due to stratification the distribution of antiemetic prophylaxis was also identical in all groups (Table 2).

The emergence times from discontinuation of the maintenance anesthetics to removal of the tracheal tube, as well as duration of stay in the recovery room were similar in all treatment groups (Table 2). Incidence and severity of pain and headache were not affected by the anesthetic technique. The need for rectal paracetamol or intravenous tramadol was similar in the four groups studied.

The incidence of postoperative nausea (PON), i. e. once or more a nausea score $>0$, was significantly smaller in group $\mathrm{P}(P=0.043)$. Since retching alone without vomiting did not occur, "emetic episodes" are defined as postoperative vomiting (POV). Propofol anesthesia was associated with a significantly lower incidence of POV (emetic episodes), $(P=$
0.011). And PONV, i. e. once or more a nausea score $>0$ and/or vomiting once or more within 24 hours, occurred less in group $\mathrm{P}$ compared to group $\mathrm{I}, \mathrm{E}$ and $\mathrm{S}(P=0.002)$, Tables 2 and 3.

\section{DISCUSSION}

Postoperative nausea and vomiting are the most frequent complications after strabismus surgery. It is striking that the reported incidences for unpleasant emetic sequelae using inhalational anesthesia ranged between 30 and $95 \%[5,10]$. Comparing those figures to our results remains difficult because only few trials characterize study groups with respect to relevant patient-related factors influencing PONV [11]. We assume that some of these effects are due to the variation in study design and some minor differences are also added to the overall observed difference regarding the investigated endpoints. Further discrepancies may be due to

Table 3. Emetic Symptoms and Rescue Treatment Per Time Interval After Extubation

\begin{tabular}{|l|c|c|c|c|c|}
\hline \multirow{2}{*}{ Characteristic } & & Group I & Group E & Group S \\
& & $\mathbf{n}=\mathbf{6 0}$ & $\mathbf{n 9}$ & $\mathbf{5 9}$ \\
\hline \hline PON & $0-2$ & $17(28 \%)$ & $16(27 \%)$ & $17(29 \%)$ & $7(12 \%)$ \\
\hline & $2-6$ & $12(20 \%)$ & $11(19 \%)$ & $5(8 \%)$ \\
\hline POV & $6-24$ & $9(15 \%)$ & $12(20 \%)$ & $10(17 \%)$ & $6(10 \%)$ \\
\hline & $0-2$ & $13(22 \%)$ & $14(24 \%)$ & $9(10 \%)$ & $2(3 \%)$ \\
\hline PONV & $2-6$ & $15(25 \%)$ & $12(20 \%)$ & $16(27 \%)$ & $7(12 \%)$ \\
\hline & $6-24$ & $14(23 \%)$ & $12(20 \%)$ & $5(8 \%)$ \\
\hline & $0-2$ & $20(33 \%)$ & $23(39 \%)$ & $14(24 \%)$ & $7(12 \%)$ \\
\hline Rescue antiemetics & $2-6$ & $18(30 \%)$ & $18(31 \%)$ & $18(31 \%)$ & $9(15 \%)$ \\
\hline & $6-24$ & $20(33 \%)$ & $20(34 \%)$ & $2(3 \%)$ & $2(15 \%)$ \\
\hline
\end{tabular}


the assessment of emetic symptoms in each trial which differs to a large extent between the trials and renders a quite difficult comparison with meaningful conclusions.

The reasons for the fairly high rates of PONV are not, as yet, understood. It has been suggested by Van den Berg that an "oculo-emetic reflex" is responsible for the high incidence of PONV following strabismus surgery [12]. Intraoperative recession and manipulation should cause more traction on eye muscle spindles, thus, via vagal and trigeminal afferents activate the vomiting system. In contrast to this proposal we were unable to find any correlation between muscle resection-length and the incidence of PONV [13]. Another hypothesis is based on an optokinetic imbalance and disturbance of visual axes [10].

However, all these considerations remained speculative. In addition, recent multivariate studies have shown age, sex duration of anesthesia and history of PONV or motion sickness as main risk factors for nausea and vomiting [3, 4]. This suggests that the incidence of PONV in strabismus surgery is mainly related to the usually high proportion of children [14]. Recent analyses have demonstrated convincingly, that in the pediatric population strabismus surgery is clearly a risk factor that needs to be taken into account when the risk for POV should be assessed in children [6].

Since motion after anesthesia seemed to contribute to emetic sequelae through stimulation of the vestibular labyrinthine system [11], especially when opioids are used as intra- or postoperative analgesic, we only included inpatients, who stayed on the ward for the first postoperative night. Reversal of neuromuscular blockade with cholinesterase inhibitors plays a contradictive role in its effect on the incidence of PONV $[15,16]$, therefore no NDMR were used throughout the study.

Antiemetic prophylaxis seemed to be justified, as the present study investigated patients with increased risk and the overall research project intended to elucidate the main contributing factors and clinically meaningful antiemetic strategies [9]. Focusing primarily on the influence of the anesthetic technique on PONV, allocation and application of antiemetic prophylaxis was randomized, stratified and double-blind to avoid heterogeneous study groups. All antiemetics administered have often been used for the prevention of PONV [17]. In this study, however, we could not find any significant differences in the incidences of PONV among the antiemetics groups, suggesting that these drugs lack antiemetic effects in patients with increased risk undergoing strabismus surgery.

Our study found a favorable effect of propofol anesthesia on PONV compared to maintenance with inhalational anesthetics. These findings are in agreement with other similar studies. Weir et al. [18] reported a significant reduction in vomiting when compared to halothane in pediatric outpatient strabismus surgery. Korttila at al. compared a thiopental/isoflurane technique to a propofol/propofol technique and found the latter to be superior with respect to prevention of vomiting [19]. Investigating a comparable anesthesia regimen, Doze et al. concluded that propofol/nitrous oxide compares favorable to thiopental/isoflurane/nitrous oxide only for short outpatient procedures but not for major abdominal surgery [20]. Watcha et al. [21] have compared different propofol-based anesthetic techniques to halothane anesthesia, supplemented with droperidol and nitrous oxide. In a disagreement with the present study, the authors only found a beneficial effect when propofol was used without $\mathrm{N}_{2} \mathrm{O}$. On the other hand, there are some topical investigations failing to show any beneficial effect of propofol on vomiting [22, 23]. Unfortunately, the number of patients per group in the cited studies with negative findings is small and no power analysis was applied. In a meta-analysis, using the number-to-treat method, Tramèr and colleagues suggested that propofol alone is not an effective means of preventing vomiting after pediatric strabismus surgery [24].

Although there may be a relationship between emesis and the use of nitrous oxide, the literature on this is far from clear $[25,26]$. Possible proemetogenic mechanisms of $\mathrm{N}_{2} \mathrm{O}$ include gut distension, actions on central opioid receptors and increase of middle ear pressure. In contrast to Watcha et al. [21], an investigation by Larsson et al. [8] revealed a lower incidence of emetic episodes in the propofol group despite the use of nitrous oxide (5\%) compared to thiopentone and halothane (27\%). It might be that omitting nitrous oxide in the propofol group would have led to a more excessive reduction of vomiting in the present study [27, 28]. However, we chose to use nitrous oxide in our investigation in order to reduce the risk of awareness and to supply additive analgesia to propofol and inhalational anesthesia [28]. The current concept regarding the relative effect of nitrous oxide is that it increases the risk for PONV but the overall resulting effect is less pronounce than omitting effective antiemetics or using inhalational anesthesia instead of propofol.

The underlying mechanisms of the lower incidences of PONV following propofol anesthesia have not yet been elucidated. It has been suggested that propofol acts as a specific antiemetic [29]. In support of this hypothesis Honkavaara et al. found propofol in subhypnotic doses to be effective in preventing retching and vomiting after isoflurane anesthesia, following middle ear surgery compared to thiopentone, without implications on patient's vigilance [30]. One possible specific antiemetic mechanism, a dopamine antagonism, was suggested by Di Florio [31] but rejected in a controlled trial, investigating the impact of propofol on serum prolactin level [32]. In a disagreement with specific antiemetic action, Hvarfner et al. pointed out that propofol and midazolam infusion were equally effective to prevent apomorphin induced emesis, while both agents exceeded the effect of placebo [33]. The latter study would support the postulation that propofol similar to other hypnotic agents such as midazolam, may exercise its antiemetic effect primarily via sedation; and intraoperative avoidance of potentially emetic drugs such as volatile anesthetics play the decisive role in the beneficial effect of propofol as a maintenance agent for anesthesia. The latter concept is the currently preferred conceptual framework.

The incidence of PONV after sevoflurane was comparable to that of isoflurane and enflurane. Our data suggest that sevoflurane compared to older inhalational agents offers no significant benefit with respect to PONV. These findings were robust in the conducted multivariate 
analyses as described elsewhere [9]. The chosen factorial design was especially suited to analyze independent risk factors [34]. It could be clearly demonstrated that in the early postoperative phase inhalational anesthetics were the most important independent factor for the occurrence of PONV [9]. Thus, the avoidance of volatile anesthetics may be more appropriate than relying on the efficacy of antiemetics [35]. This is especially true for the high risk patients if the aim is to retain an intervention for rescue treatment. This finding supports the figures of a large phase III study by Campbell et al. comparing sevoflurane to isoflurane [36] but it is in contrast with a study of Wiesner and colleagues [37], as well as Phillip et al. [38] who reported a significant lower incidence of nausea in the sevoflurane group compared to isoflurane. For nausea as a subjective complaint is difficult to assess, therefore a comparison of the data should be made with caution.

\section{CONCLUSION}

In conclusion, in 238 patients undergoing strabismus surgery, the use of propofol for induction and maintenance of anesthesia was an effective mean to reduce the overall incidence of postoperative nausea and vomiting over 24 hours compared to inhalational anesthesia. Between the volatile agents isoflurane, enflurane and sevoflurane, we were unable to find any significant differences in emetogenicity.

\section{ACKNOWLEDGEMENTS}

Our warm thanks to the ophthalmologists, anesthesia personnel and nurses of the Department of Ophthalmology, Würzburg, Germany, for their interest and support during the study.

\section{REFERENCES}

[1] Patel RI, Hannallah RS. Anesthetic complications following pediatric ambulatory surgery: a 3-yr study. Anesthesiology 1988; 69: 1009-12.

[2] van Wijk MG, Smalhout B. A postoperative analysis of the patient's view of anesthesia in a Netherlands' teaching hospital. Anesthesia 1990; 45: 679-82.

[3] Koivuranta M, Läärä E, Snare L, Alahuhta S. A survey of postoperative nausea and vomiting. Anesthesia 1997; 52: 443-9.

[4] Apfel CC, Greim CA, Haubitz I, et al. A risk score to predict the probability of postoperative vomiting in adults. Acta Anesthesiol Scand 1998; 42: 495-501.

[5] Klockgether-Radke A, Neumann S, Neumann P, Braun U, Muhlendyck H. Ondansetron, droperidol and their combination for the prevention of post-operative vomiting in children. Eur J Anesthesiol 1997; 14: 362-7.

[6] Eberhart LH, Geldner G, Kranke P, et al. The development and validation of a risk score to predict the probability of postoperative vomiting in pediatric patients. Anesth Analg 2004; 99: 1630-7.

[7] Kranke P, Eberhart LH, Toker H, Roewer N, Wulf H, Kiefer P. A prospective evaluation of the POVOC score for the prediction of postoperative vomiting in children. Anesth Analg 2007; 105: $1592-7$.

[8] Larsson S, Asgeirsson B, Magnusson J. Propofol-fentanyl anesthesia compared to thiopental-halothane with special reference to recovery and vomiting after pediatric strabismus surgery. Acta Anesthesiol Scand 1992; 36: 182-6.

[9] Apfel CC, Kranke P, Katz MH, et al. Volatile anesthetics may be the main cause of early but not delayed postoperative vomiting: a randomized controlled trial of factorial design. $\mathrm{Br} \mathrm{J}$ Anesth 2002; 88: 659-68.

[10] Lermann J. Surgical and patient factors involved in postoperative nausea and vomiting. Br J Anesth 1992; 69: 20S-3S.
[11] Korttila K. The study of postoperative nausea and vomiting. Br J Anesth 1992; 69: 20S-3S.

[12] Van den Berg AA, Lambourne A, Clyburn PA. The oculo-emetic reflex: a rationalisation of postophthalmic anesthesia vomiting. Anesthesia 1989; 44: 110-7.

[13] Papenfuss T, Apfel CC, Schäfer WD, et al. Is there a correlation between postoperative vomiting and increased extraocular muscle tone in strabismus surgery? Br J Anesth 1998; (Suppl 1): A 119.

[14] Papenfuss T, Apfel CC, Kranke P, Goepfert C, Sefrin P, Roewer N. Is age a main cause for the high incidence of postoperative vomiting in strabismus surgery? Anästhesiol Intensivmed Notfallmed Schmerzther 1998; 33: S 413.

[15] King MJ, Milazkiewicz R, Carli F, Deacock AR. Influence of neostigmine on postoperative vomiting. $\mathrm{Br} \mathrm{J}$ Anesth 1988; 61: 403-6.

[16] Boeke AJ, de Lange JJ, van DB, Langemeijer JJ. Effect of antagonizing residual neuromuscular block by neostigmine and atropine on postoperative vomiting. Br J Anesth 1994; 72: 654-6.

[17] Rowbotham DJ. Current management of postoperative nausea and vomiting. Br J Anesth 1992; 69: 46S-59S.

[18] Weir PM, Munro HM, Reynolds PI, Lewis IH, Wilton NC. Propofol infusion and the incidence of emesis in pediatric outpatient strabismus surgery. Anesth Analg 1993; 76: 760-4.

[19] Korttila K, Ostman P, Faure E, et al. Randomized comparison of recovery after propofol-nitrous oxide versus thiopentoneisoflurane-nitrous oxide anesthesia in patients undergoing ambulatory surgery. Acta Anesthesiol Scand 1990; 34: 400-3.

[20] Doze VA, Shafer A, White PF. Propofol-nitrous oxide versus thiopental-isoflurane-nitrous oxide for general anesthesia. Anesthesiology 1988; 69: 63-71.

[21] Watcha MF, Simeon RM, White PF, Stevens JL. Effect of propofol on the incidence of postoperative vomiting after strabismus surgery in pediatric outpatients. Anesthesiology 1991; 75: 204-9.

[22] Hamunen K, Vaalamo MO, Maunuksela EL. Does propofol reduce vomiting after strabismus surgery in children? Acta Anesthesiol Scand 1997; 41: 973-7.

[23] Habre W, Sims C. Propofol anesthesia and vomiting after myringoplasty in children. Anesthesia 1997; 52: 544-6.

[24] Tramèr MR, Moore A. Prevention of vomiting after pediatric strabismus surgery: a systematic review using the numbers-neededto-treat method. Br J Anesth 1995; 75: 556-61.

[25] Melnick BM, Johnson LS. Effects of eliminating nitrous oxide in outpatient anesthesia. Anesthesiology 1987; 67: 982-4.

[26] Korttila K, Hovorka J, Erkola O. Nitrous oxide does not increase the incidence of nausea and vomiting after isoflurane anesthesia. Anesth Analg 1987; 66: 761-5.

[27] Hartung J. Twenty-four of twenty-seven studies show a greater incidence of emesis associated with nitrous oxide than with alternative anesthetics. Anesth Analg 1996; 83: 114-6.

[28] Tramèr MR, Moore A, McQuay H. Omitting nitrous oxide in general anesthesia: meta-analysis of intraoperative awareness and postoperative emesis in randomized controlled trials. $\mathrm{Br} \mathrm{J}$ Anesth 1996; 76: 186-93.

[29] Borgeat A, Wilder-Smith OH, Saiah M, Rifat K. Subhypnotic doses of propofol possess direct antiemetic properties. Anesth Analg 1992; 74: 539-41.

[30] Honkavaara P, Saarnivaara L. Comparison of subhypnotic doses of thiopentone $v s$ propofol on the incidence of postoperative nausea and vomiting following middle ear surgery. Acta Anesthesiol Scand 1998; 42: 211-5.

[31] DiFlorio T. Is propofol a dopamine antagonist? Anesth Analg 1993; 77: 200-1.

[32] Borgeat A. Subhypnotic doses of propofol do not possess antidopaminergic properties. Anesth Analg 1997; 84: 196-8.

[33] Hvarfner A, Hammas B, Thorn SE, Wattwil M. The influence of propofol on vomiting induced by apomorphine. Anesth Analg 1995; 80: 967-9.

[34] Apfel CC, Korttila K, Abdalla M, et al. An international multicenter protocol to assess the single and combined benefits of antiemetic interventions in a controlled clinical trial of a $2 \times 2 \times 2 \times 2 \times 2 \times 2$ factorial design (IMPACT). Control Clin Trials 2003; 24: 736-51.

[35] Carlisle JB, Stevenson CA. Drugs for preventing postoperative nausea and vomiting. Cochrane Database Syst Rev 2006; 3 : CD004125. 
[36] Campbell C, Andreen M, Battito MF, et al. A phase III, multicenter, open-label, randomized, comparative study evaluating the effect of sevoflurane versus isoflurane on the maintenance of anesthesia in adult ASA class I, II, and III inpatients. J Clin Anesth 1996; 8: 557-63.

[37] Wiesner G, Schwurzer S, Horauf K, Hobbhahn J. Emergence times, hemodynamics and adverse effects of sevoflurane and isoflurane: an open, randomized, comparative phase iii study. Der Anesthesist 1994; 43: 587-93.

[38] Philip BK, Kallar SK, Bogetz MS, Scheller MS, Wetchler BV. A multicenter comparison of maintenance and recovery with sevoflurane or isoflurane for adult ambulatory anesthesia. The Sevoflurane Multicenter Ambulatory Group. Anesth Analg 1996; 83: 314-9.

Received: October 17, 2008

(C) Kranke et al.; Licensee Bentham Open.

This is an open access article licensed under the terms of the Creative Commons Attribution Non-Commercial License (http://creativecommons.org/licenses/by$\mathrm{nc} / 3.0 /$ ) which permits unrestricted, non-commercial use, distribution and reproduction in any medium, provided the work is properly cited. 